\title{
MULHERES NO SEGUNDO E TERCEIRO TRIMESTRES DE GRAVIDEZ: SUAS ALTERAÇÕES PSICOLÓGICAS ${ }^{1}$
}

\author{
WOMEN IN SECOND AND THIRD TRIMESTER OF PREGNANCY: \\ PSYCHOLOGICAL CHANGES

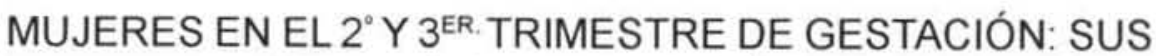 \\ ALTERACIONES PSICOLÓGICAS
}

Luciana de Lione Melo²

Maria Alice Dias da Silva Lima ${ }^{3}$

\begin{abstract}
RESUMO: O propósito do artigo é relatar a experiência das autoras ao coordenar um grupo de gestantes, que teve a finalidade de esclarecer algumas dúvidas sobre o periodo gestacional, cuidados com o recém-nascido e anticoncepção. Aborda as percepçōes e sentimentos das gestantes a respeito do tema sexualidade e aspectos psicológicos da gravidez. As alteraçōes psicológicas apresentadas pelas gestantes no segundo e terceiro trimestres da gravidez evidenciam a importância da função educadora da enfermeira no trabalho com grupos.
\end{abstract}

PALAVRAS-CHAVE: sexualidade na gravidez, aspectos psicológicos da gravidez

\section{INTRODUÇĀO}

Este artigo relata uma experiência desenvolvida como atividade da disciplina de Administração de Enfermagem em Unidade de Saúde Pública, do curso de graduação da Escola de Enfermagem da Ribeirão Preto da Universidade de São Paulo. Como parte do processo de avaliação da referida disciplina foi solicitado a elaboração de uma proposta de atuação e seu desenvolvimento, referente ao setor escolhido para o estágio em uma Unidade Básica de Saúde de Ribeirão Preto.

Nossa proposta foi a de formar um grupo de gestantes, com o objetivo de esclarecer dúvidas sobre periodo gestacional, cuidados com o recém-nascido e alguns aspectos sobre anticoncepção. Como coordenadoras, decidimos que durante o primeiro encontro discutiriamos no grupo os temas, com o intuito de sabermos quais as dúvidas das gestantes e após este momento fixariamos os mesmos. Estes foram distribuidos conforme descrito a seguir.

No primeiro encontro abordamos a finalidade do grupo, apresentação das participantes, dúvidas sobre o assunto, discussão dos temas a serem desenvolvidos nos encontros posteriores, além de esclarecermos que parte das informações obtidas poderia ser usado para um trabalho posterior, se assim as participantes do grupo concordassem. Entregamos o termo de consentimento informado, que foi assinado por todas as participantes. O segundo encontro contemplou aspectos referentes à anatomia e fisiologia do corpo humano e à fecundação.

Questões relativas à sexualidade e aspectos psicológicos da gravidez foram abordadas no terceiro encontro e, na reunião posterior do grupo foram tratados os tipos de parto, trabalho

\footnotetext{
' Este trabalho foi realizado como atividade do Programa de Aperfeiçoamento de Ensino (PAE) da Escola de Enfermagem de Ribeirāo Preto-USP.

${ }^{2}$ Enfermeira. Doutoranda do Programa Interunidades de Doutoramento em Enfermagem da EERP-USP.

${ }^{3}$ Enfermeira, Professora Assistente da Escola de Enfermagem da Universidade Federal do Rio Grande do Sul,
} 
de parto e alojamento conjunto. O quinto e o sexto encontros foram dirigidos para explicações sobre os cuidados com o recém-nascido, amamentação e puerpério e na última reunião do grupo, na qual houve o encerramento das atividades do grupo, abordamos alguns aspectos sobre anticoncepção.

Buscando relatar uma experiência que foi desenvolvida e ao mesmo tempo aprofundar algumas das questões já mencionadas, este trabalho tem como propósito:

- Identificar as percepções das gestantes a respeito de temas pertinentes a sexualidade e aspectos psicológicos da gravidez.

\section{ASPECTOS PSICOLÓGICOS DAGRAVIDEZ}

Maldonado (1985) afirma que a gravidez é um periodo de transição biologicamente determinado, caracterizado por mudanças metabólicas complexas, estado temporário de equilibrio instável devido às grandes perspectivas de mudanças envolvidas nos aspectos de papel social, necessidade de novas adaptações, reajustamentos intrapessoais e intrapsíquicos e mudança de identidade.

Além das mudanças físicas amplamente descritas por estudiosos da área, há também as mudanças psicológicas. Rancurel e Marmie (1975) falam que mesmo as gravidezes mais «normais» apresentam modificaçőes psicológicas. Toda mulher grávida experimenta certa angústia que se exprimiria nos sonhos, nos problemas com o sono, nos temores conscientemente ditos. Também seriam, as modificações do paladar, os desejos, fases de irritabilidade, de instabilidade de humor com passagens rápidas dos sorrisos às lágrimas. Poder-se-ia ver a alternância de periodos de ciúmes e indiferença e desregramento dos apetites sexuais, além de uma certa lentificação de idéias e apatia levando a sonolência.

Assim, percebemos que a gravidez é um processo fisiológico que envolve alterações profundas, cujas repercussões vão se fazer sentir física, psiquica e socialmente, pois envolve necessidade de reestruturação e reajustamento em várias dimensões.

As alterações psicológicas da gravidez estão divididas em três trimestres apenas para fim didático. Abordaremos apenas os aspectos relativos à caracterização do segundo e terceiro trimestres, devido à idade gestacional que as gestantes que participaram do grupo se encontravam.

O segundo trimestre é considerado o mais estável do ponto de vista emocional. O impacto dos primeiros movimentos fetais é um fenômeno central neste trimestre - é a primeira vez que a mulher sente o feto como uma realidade concreta dentro de si, como um ser separado dela e no entanto tão dependente, mas já com caracteristicas próprias. As alterações do desejo e do desempenho sexual tendem a surgir com maior intensidade a partir deste momento.

Maldonado (1985) acredita que o aspecto dinâmico básico é a mudança da percepção de si própria. No entanto, mais comumente verificam-se graus variados de diminuição do desejo sexual, tanto por parte da mulher quanto do homem. Alguns fatores etiológicos possiveis citados pela referida autora : a cisão entre maternidade e sexualidade - a sensação de que a mulher grávida é "pura" e assexuada ; uma das manifestações de ambivalência: o medo de machucar o feto motiva a formação de excessiva cautela, sendo importante considerar a influência de fatores culturais na sexualidade durante e após a gravidez.

Um dos temores mais universais da gravidez está associado às alterações corporais : medo de não voltar a forma anterior a gestação, ficando flácida após o parto. Este temor, além do seu aspecto objetivo, pode ter um significado simbólico mais profundo: o medo de ficar modificada como pessoa pela experiência da maternidade, de não mais recuperar sua identidade antiga e tranformar-se numa outra pessoa.

A introversão e a passividade constituem caracteristicas emocionais das mais comuns na gravidez. Este aspecto ocorre por modificaçōes metabólicas necessárias na preparação 
para o papel da mãe. Neste período também, a mulher sente maior necessidade de afeto, cuidados e proteção.

No terceiro trimestre, o nivel de ansiedade deve elevar-se novamente com a proximidade do parto e da mudança de rotina da vida após a chegada do bebê. $A$ ansiedade é maior principalmente nos dias que antecedem a data prevista do parto e tende a intensificar-se quando esta é ultrapassada.

Barbieri (1983) ressalta que para algumas parturientes esta é a primeira experiência de internação hospitalar, sendo válido tanto para primiparas como para multiparas, pois estas podem ter tido somente experiência de parto domiciliar. O hospital é sempre um ambiente estranho para ela e sua familia.

Algumas reações podem ser geradas por preocupações relativas ao próprio trabalho de parto como: ter medo das "dores" decorrentes da contração uterina, preocupar-se com o que vai acontecer com ela e com seu filho, temer pela ocorrência de uma experiência traumatizante $e$ ainda medo de morrer no parto.

\section{METODOLOGIA}

O grupo de gestantes foi realizado em uma creche, situada na área de abrangência de uma Unidade Básica de Saúde. Os encontros ocorreram às terças e quintas-feiras, das 14:00 às 15:00 horas. As reuniões foram feitas numa sala, onde as cadeiras eram dispostas em círculo e as gestantes sentavam sem lugar determinado.

A população foi composta por cinco gestantes, porém no encontro que tratava do assunto que está sendo enfocado, compareceram apenas quatro.

Ao iniciar a exposição do tema, do qual as gestantes participavam, anotávamos suas percepçöes quanto aos aspectos relevantes, tais como sentimentos pela descoberta da gravidez e pelas modificações corporais, primeiros movimentos fetais, relacionamento com o companheiro e o que este sente com relação a sua companheira, qual a sua expectativa após o parto. Os dados relativos às suas percepções são descritos a seguir.

\section{APRESENTAÇÄO E DISCUSSÃO DOS DADOS}

Agrupamos os dados em algumas categorias temáticas, considerando a literatura específica. Desta forma, emergiram as seguintes categorias: 1. Modificações corporais; 2. Relacionamento familiar; 3. Relacionamento sexual e 4. Expectativas pós-parto.

\section{Modificações corporais}

Apesar das modificações corporais ocorrerem lentamente, as gestantes vivenciaram estas mudanças de maneiras diversas:

Foi devagar, mas sinto-me feliz. (1)

Gostei... é bom.(2)

Estranhei no inicio, sentia-me outra pessoa.(3)

Sentia-me feia e gorda, agora sinto-me bem.(4)

Além de verbalizarem sobre as modificações corporais em geral, a modificação mais relatada pelo grupo foi sentir o feto mexer.

Senti medo, agora eu gosto.(1)

Gosto, sinto prazer.(2)

Fiquei surpresa, mas agora gosto.(3)

A primeira vez eu assustei, mas agora gosto.(4)

Os primeiros movimentos fetais são recebidos pelas mulheres com certa apreensão e 
medo, porém logo acostumam-se e passam a gostar, relacionando-os com a personalidade do bebê. Um estudo de Bonnauld e D'Allones citado por Maldonado (1985) mostrou que a percepção dos primeiros movimentos fetais tende a favorecer a aceitação da gravidez em $85 \%$ dos casos estudados; já as modificações corporais causam menor ansiedade, pois são gradativas, porém uma gestante ressaltou que no primeiro trimestre sentia-se feia, mas agora sente-se bem.

\section{Relacionamento familiar}

Algumas mulheres referiram que seus relacionamentos familiares durante a gestação tomaram-se conturbados e outras que em seus relacionamentos não houve qualquer alteração.

No início eu brigava muito com os meusimãos, agora estou mais calma.(1) Sinto-me bem e muito feliz. Minha familia está dando muito apoio.(2) No início eu estava muito irnitada, brigava com minha mãe, com meu filho e com meu marido. Agora estou mais calma.(3)

A literatura sugere-nos que as mudanças no relacionamento familiar estão ligadas ao desejo ou não de engravidar e de ter um filho. A familia que esperava por essa gravidez tende a ter um bom relacionamento e o oposto se verifica em familias onde a gravidez não foi planejada (Soifer, 1980)

\section{Relacionamento sexual}

A literatura traz que as alterações do desejo e do desempenho sexual tendem a surgir com maior intensidade a partir do segundo trimestre, embora às vezes se manifestem desde 0 início da gravidez. É raro observar aumento da sexualidade, porém algumas mulheres experimentam o orgasmo pela primeira vez durante a gravidez. De modo geral, as gestantes do grupo em estudo, referiram diminuir o número de relaçōes sexuais e apenas uma referiu não as ter durante a gestação.

Tenho poucas relações sexuais e sinto-me bem, porém quando o nené mexe durante a relação sexual, sinto vontade de parar.(1)

Tenho poucas relaçס̃es sexuais e sinto-me bem.(2)

Não gosto de ter relações sexuais quando estou grávida e meu marido concorda.(3)

O grupo em estudo vem corroborar com Maldonado (1985) que afirma que o mais comum é uma diminuição do desejo sexual, chegando até ao desinteresse total por parte da mulher e às vezes, por parte do homem.

\section{Expectativas pós-parto}

Considerando que todas as gestantes encontram-se próximas ao final da gestação, as mesmas ressaltaram que querem que seus corpos voltem a forma normal após o nascimento do bebê:

Espero voltar a forma física normal.(1)

Năo quero ficar gorda, quero voltar ao normal.(2)

Um dos temores mais universais da gravidez está associado às alteraçöes do esquema corporal: o medo da irreversibilidade, a dificuldade em acreditar que o corpo tem a capacidade de voltar ao estado anterior à gravidez (Maldonado, 1985). 


\section{CONSIDERAÇÕES FINAIS}

Durante o período pré-natal o trabalho da enfermeira é de extrema importância junto à gestante, de maneira a orientar na solução de problemas sociais e de saúde, específicos em cada caso, através da orientação e ensino que deve abranger todo ciclo vital da mulher. A função de educadora acentua-se cada vez mais e neste aspecto a enfermeira deixa de ser o elemento que transmite conceitos e regras, para se transformar no elemento chave da dinâmica de relacionamento, transformando a orientação sistemática e rotineira, onde o ponto principal é a necessidade de ensinar em grupos de trabalho para gestantes, onde as próprias mães determinam o conteúdo de suas discussões, trazendo as necessidades por elas sentidas.

Sendo o parto em si, um grande gerador de tensão como já mencionado anteriormente, é necessário que haja também orientação para o parto, já que este é um periodo dinâmico e marco de normalidade e não de enfermidade. Para Phillips (1994) a assistência ao parto deve ser individualizada pois as mulheres e suas famílias experimentam de modo diferente o processo de dar à luz, devendo a mãe e o bebê serem atendidos como uma unidade e não como pacientes individuais. Além disso, o autor considera que a educação é parte integral para a assistência a maternidade, influenciando na tomada de decisões pelas mulheres e criando uma sensação de bem estar durante o trabalho de parto.

A experiência de coordenar um grupo de gestantes pela primeira vez, deixou-nos satisfeitas com o resultado obtido, pois acreditamos que para o sucesso de um grupo, faz-se necessário o estabelecimento de vínculos entre os participantes, contribuindo desse modo para que possamos trocar experiências, rumando a maturidade. Consideramos de extrema importância a formação de grupos que objetivam não apenas ensinar, mas também aprender e havendo todo este processo, beneficiariamos as gestantes ajudando-as a enfrentar o periodo de gestação, preparando-as a vencer obstáculos que estão por vir e ainda cresceriamos profissionalmente através da contínua busca de conhecimento.

ABSTRACT: The purpose of the paper is to report the authors' experience with a group of pregnant women when coordinating a project in which the objective was to clarify doubts about pregnancy, care of the newborn and contraception. It focuses on the feelings and perceptions of these women regarding the theme of sexuality and psychological aspects of pregnancy. The psychological changes mentioned by the participants in the second and third trimester made evident the importance of the nursing worker's educational when dealing with groups.

KEYWORDS: sexuality in pregnancy, psychological aspects of pregnancy

RESUMEN: El propósito del articulo es relatar la experiencia de las autoras al coordinar un grupo de embarazadas, cuya finalidad fue la de aclararles algunas dudas sobre el periodo de la gestación, cuidados al recién nacido y sobre la anticoncepción. Se enfocaron las percepciones y los sentimientos de las gestantes frente a la temática de la sexualidad y los aspectos psicológicos del embarazo. Las alteraciones psicológicas que las embarazadas presentaron en el segundo y tercer trimestre del embarazo, evidencian la importancia que la función educadora de la enfermera tiene en el trabajo con grupos.

PALABRAS CLAVE: sexualidad en el embarazo, aspectos psicológicos del embarazo 


\section{REFERÊNCIAS BIBLIOGRÁFICAS}

BARBIERI, D.L. et al. Assistência a parturiente : alguns aspectos psicossociais, Rev. Esc. Enf. USP, v.17, n.1, p.33-37, 1983.

MALDONADO, M.T.P. Psicologia da Gravidez : parto e puerpério. Petrópolis, Vozes, 1985. 163p.

PHILLIPS, C, et al. Atención de maternidad para el siglo XXI. El hospital, v. 50, n. 4, p. 3-10, 1994.

RANCUREL, G.; MARMIE, D. Psychoses puerpérales. Les acidents psychiatriques et les manifestations psychopatologiques de la gravido - puerpéralité. In : Encyclopédie Médico Chirurgicale. Psichiatrie. Paris, EditionsTechniques, v.4, 1975.

SOIFER, R. Psicologia da gravidez: parto e puerpério. Porto Alegre, Artes Médicas, 1980. 124p. 